\title{
Initial Firing Angle Control of Parallel Multi-Pulse Thyristor Dual Converter for Urban Railway Power Substations
}

\author{
Sung-An Kim*, Sung-Wo Han** and Yun-Hyun Cho ${ }^{\dagger}$
}

\begin{abstract}
This paper presents an optimal initial firing angle control based on the energy consumption and regenerative energy of a parallel multi-pulse thyristor dual converter for urban railway power substations. To prevent short circuiting the thyristor dual converter, a hysteresis band for maintaining a zero-current discontinuous section (ZCDS) is essential during mode changes. During conversion from the ZCDS to forward or reverse mode, the DC trolley voltage can be stabilized by selecting the optimal initial firing angle without an overshoot and slow response. However, the optimal initial firing angle is different depending on the line impedance of each converter. Therefore, the control algorithm for tracking the optimal initial firing angle is proposed to eliminate the overshoot and slow response of DC trolley voltage. Simulations and experiments show that the proposed algorithm yields the fastest DC voltage control performance in the transient state by tracking the optimal firing angle.
\end{abstract}

Keywords: Thyristor dual converter, Initial firing angle, DC voltage control, Power substations

\section{Introduction}

Urban railway trains generate a large amount of energy when applying regenerative braking in subway stations. Regenerative energy is currently harvested in two ways in railway power substations: by using storage systems and by feeding energy back to the distribution grid.

Devices for storing regenerative energy can be classified into four categories [1]. First, a battery storage system (BESS) can be installed in parallel with the power substations [2]. This system can reduce the energy consumption by the braking resistor. However, the BESS has disadvantages such as the short battery lifetime, limitations on charge-discharge cycles, and lower efficiency. Second, a superconducting magnetic energy storage system (SMES) performs well in terms of the efficiency (which exceeds 95\%), charge and discharge time, long lifetime, and lower maintenance cost [3]. Disadvantages of the SMES include limited production, the high cost of superconducting materials, and the ecological effects of the high-intensity magnetic field [1]. Third, the flywheel energy storage system has been studied [4, 5]. However, in urban railway power substations, this system cannot supply long-term energy storage because it is suitable for a short discharge time and high-power applications. Finally, an ultra-capacitor energy storage system differs from a BESS in that it has very high capacitance. However, it

$\dagger$ Corresponding Author: Dept. of Electrical Engineering, Dong-A University, Korea.(yhcho@dau.ac.kr)

* Dept. of Electrical and Electronic Engineering, Dong-A University, Korea. (y3k9s1@nate.com)

** R\&D Center of Busan Transportation Corporation, Korea. (h111641@humetro.busan.kr)

Received: December 7, 2015; Accepted: October 28, 2016 has disadvantages such as voltage fluctuations, short service life, and low operation reliability for regenerative energy systems.

There are two types of regenerative energy systems for feeding energy back to the distribution grid. In the regenerative inverter system using an insulated-gate bipolar transistor (IGBT), the power factors can be controlled, and the system generates high-quality voltage waveforms. However, it cannot absorb the regenerative energy from several trains on high-traffic railways because IGBT inverters have low power density per volume. The thyristor dual converter has advantages in terms of fast response and high power density per volume compared with the IGBT inverter. Therefore, the thyristor dual converter is still used in many railway power substations.

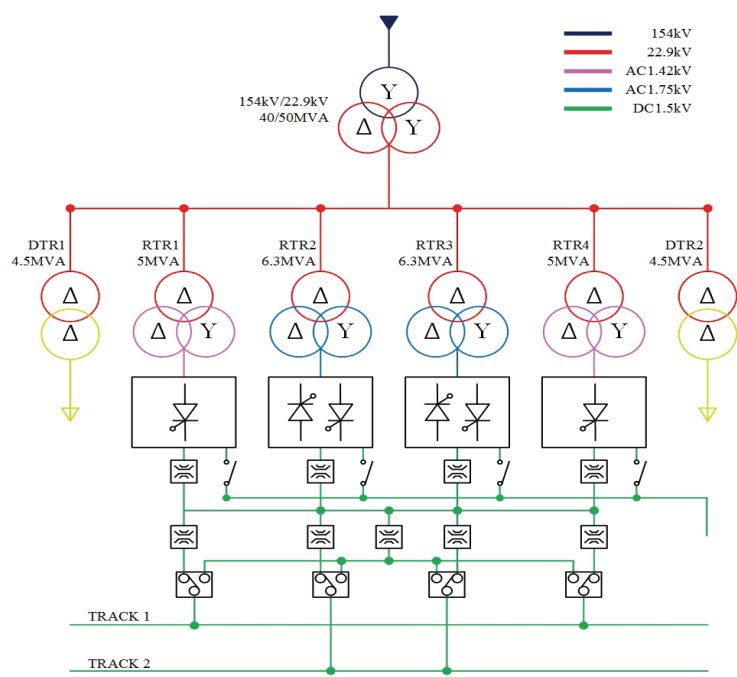

Fig. 1. Urban railway power substations 
The converter's control scheme has three operating modes depending on the electric energy flow of trains. When a train departs a subway station, it accelerates to its maximum speed and then maintains a constant speed. During this time, the converter operates in forward mode to supply power to the train. When the train slows, the DC voltage at the trolley bus rises because of regenerative energy of regenerative braking. If the DC trolley voltage exceeds its upper limit, the converter operates in reverse mode to feed energy back to the distribution grid. However, a zero-current discontinuous section (ZCDS) is required to prevent short-circuiting of the parallel connected thyristor dual converter. During conversion from the ZCDS to forward/reverse mode, an overshoot and slow response of the DC trolley are generated because of an initial firing angle. To reduce the overshoot and slow response, the initial firing angle was experimentally selected by the fixed constant values [6]-[10]. However, the optimal firing angle varies with the percentage impedance of the traction transformers, AC filter impedance, DC filter impedance, and line impedance.

In this paper, the control algorithm for calculating the optimal initial firing angle is proposed to eliminate the overshoot and slow response of DC trolley voltage. The performance of the proposed control algorithm is verified through various simulations and experiments.

\section{Voltage Control of Parallel Multi-Pulse Thyristor Dual Converter}

\subsection{Nomenclature}

$\begin{array}{ll}V_{d c} & \text { DC trolley voltage, V } \\ V_{l l}^{\prime} & \text { AC trolley line-to-line voltage, V } \\ V_{l l} & \text { AC trolley line-to-line input voltage, V } \\ V_{\text {ref }} & \text { Reference value of DC trolley voltage, V } \\ I_{\text {ref }} & \text { Reference value of DC trolley current, V } \\ I_{d c} & \text { DC trolley current, A } \\ I_{d c} \Delta & \text { DC trolley current of } \Delta \text { converter, A } \\ I_{d c} Y & \text { DC trolley current of Y converter, A } \\ V_{\max }, V_{\min } & \text { Upper and lower voltage limits, V } \\ I_{\max }, I_{\min } & \text { Upper and lower current limits, A } \\ \alpha & \text { Firing angle, } \\ P_{\text {out }} & \text { Output value of PI controller, p.u. } \\ P_{o} & \text { Output Power, W. } \\ K_{f o r}, K_{\text {rev }} & \text { Initial } P I_{o u t} \text { of forward/reverse mode } \\ t_{0}, t_{1}, t_{2}, t_{3} & \text { Response points of } V_{d c} \\ T_{1}, T_{2}, T_{3} & \text { Response section of } V_{d c} \\ K & \text { Incremental } P I_{o u t} \\ K_{p}, K_{i}, K_{c} & \text { Gain of PI controller, p.u. }\end{array}$

\subsection{Configuration of thyristor dual converter}

Fig. 1 shows the urban railway power substations located at the Hopo commuter subway in Korea. Fig. 2

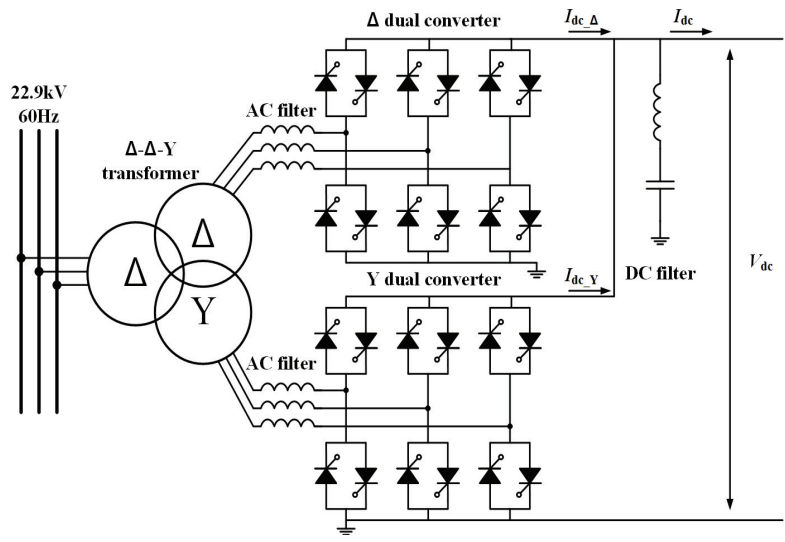

Fig. 2. Block diagram of parallel multi-pulse dual thyristor converter

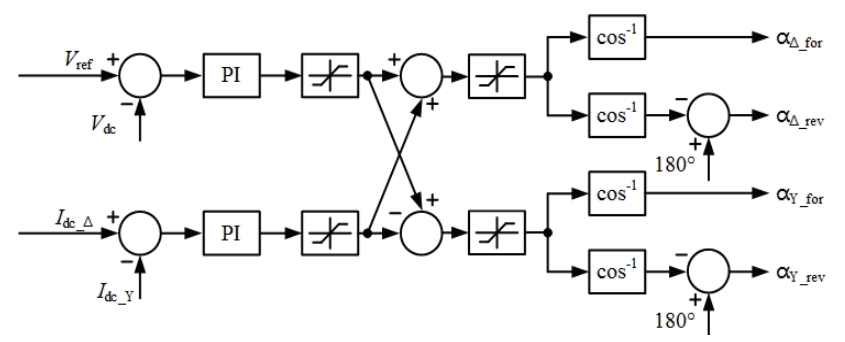

Fig. 3. Block diagram of voltage controller with differential current controller

shows a block diagram of a parallel multi-pulse thyristor dual converter.

The average DC voltage is a function of the firing angle $\alpha$ when the converter current is in the continuous section $[11,12]$ :

$$
V_{d c}=\frac{2 \sqrt{3} V_{l l}}{\pi} \cos \alpha
$$

Where $V_{l l}$ is the line-to-line input voltage. The firing angle for voltage control is obtained as follows:

$$
\alpha=\cos ^{-1}\left(\frac{\pi V_{d c}}{2 \sqrt{3} V_{l l}}\right)=\cos ^{-1}\left(P I_{\text {out }}\right)
$$

Fig. 3 shows a block diagram of a voltage controller with a differential current controller. The differential current controller is used to prevent unbalanced current between the $\Delta$ and $\mathrm{Y}$ thyristor dual converters [7]. The voltage controller calculates the firing angle to ensure the stability of the DC voltage. However, the DC trolley voltage in railway power substations varies with the energy consumption and regenerative energy generated by trains. During mode changes, the response characteristic of the DC trolley voltage varies with the initial firing angle [10]. Therefore, the initial firing angle selection is very important. 
Table 1. Relationship of points and sections

\begin{tabular}{c|c|c}
\hline Points & Sections & Priority \\
\hline$t_{0}-t_{1}$ & $T_{1}$ & 2 \\
\hline$t_{1}-t_{2}$ & $T_{2}$ & 3 \\
\hline$t_{2}-t_{3}$ & $T_{3}$ & 1 \\
\hline
\end{tabular}

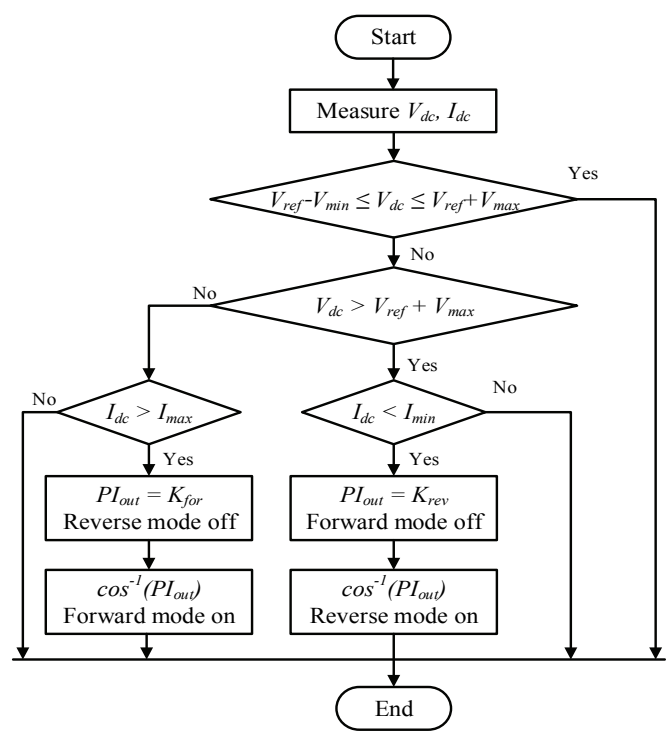

Fig. 4. Flow chart of conventional control

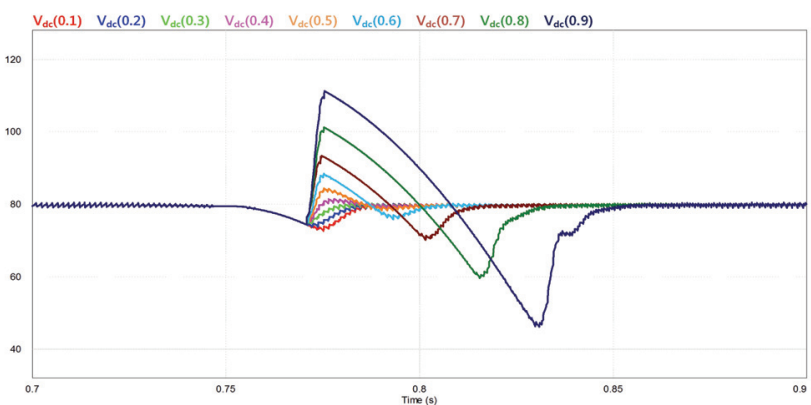

(a)

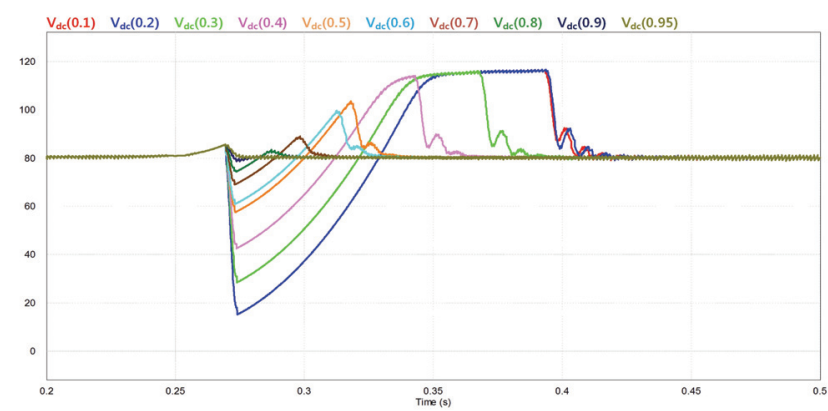

(b)

Fig. 5. Response characteristics of $V_{d c}$ according to constant values of initial $P I_{\text {out }}$ : (a) Forward mode (b) Reverse mode

\subsection{Conventional voltage control}

Fig. 4 shows a flow chart of the conventional control algorithm to control the DC trolley voltage in both forward and reverse modes. After $V_{\mathrm{dc}}$ and $I_{\mathrm{dc}}$ are measured, $V_{\mathrm{dc}}$ is compared with $V_{\text {ref }}-V_{\text {min }} \leq V_{\text {dc }} \leq V_{\text {ref }}+V_{\text {max }}$, and then $I_{\text {dc }}$ is compared with $I_{\mathrm{dc}}>I_{\max }, I_{\mathrm{dc}}<I_{\min }$. Consequently, there are two possibilities for the operating mode. If $V_{\mathrm{dc}}<V_{\text {ref }}-V_{\text {min }}$ and $I_{\mathrm{dc}}>I_{\max }$, the forward mode is used. If $V_{\mathrm{dc}}>V_{\mathrm{ref}}-V_{\max }$ and $I_{\mathrm{dc}}<I_{\min }$, the reverse mode is used. Otherwise, the discontinuous mode is used to prevent short circuiting of the parallel connected dual thyristor converter. When the forward or reverse mode is started, constant values are applied to $K_{\text {for }}$ and $K_{\text {rev }}$. These values are experimentally selected because they depend on the percentage impedance of the traction transformers, AC filter impedance, DC filter impedance, and line impedance. Fig. 5 shows response characteristics of $V_{D C}$ according to constant values of initial $P I_{\text {out }}$ during conversion from the ZCDS to the forward/reverse mode. In forward mode, when the initial $P I_{\text {out }}$ value increases, the $V_{D C}$ has slow response and a large

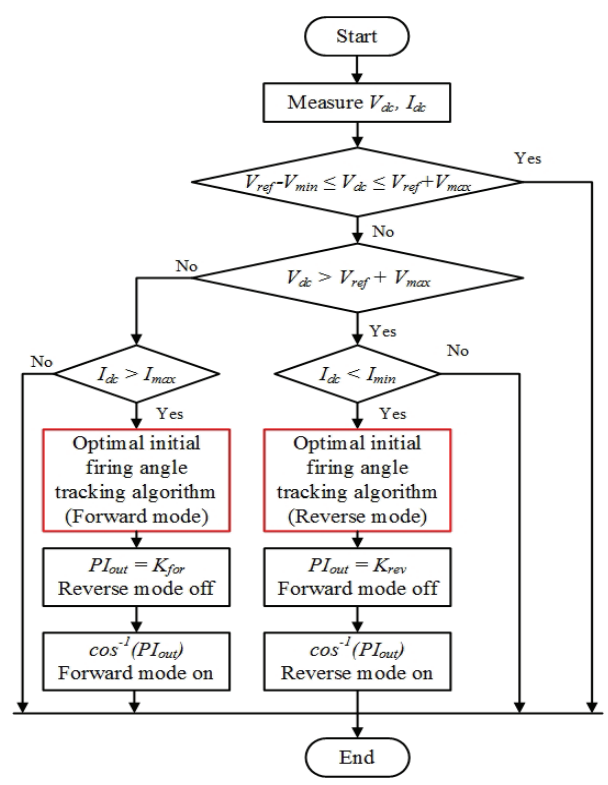

(a)

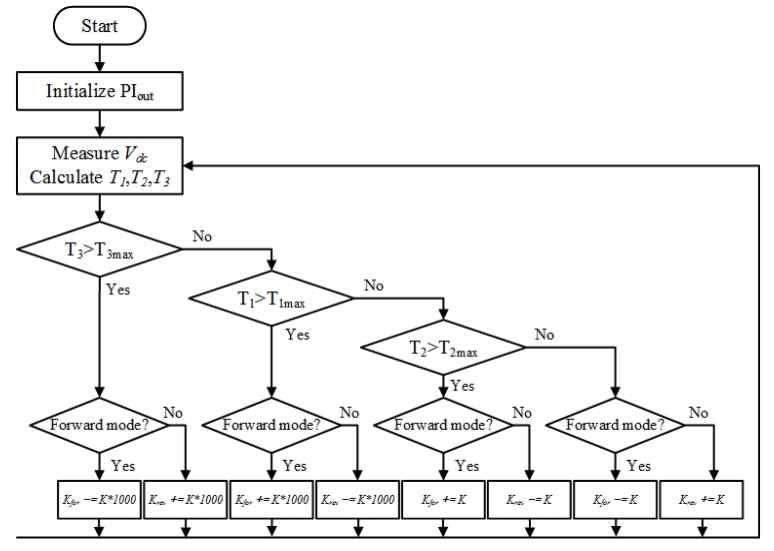

(b)

Fig. 6. Flow chart of proposed control algorithms: (a) Proposed voltage control algorithm (b) Optimal initial firing angle tracking algorithm 
overshoot. In contrast, in reverse mode, $P I_{\text {out }}$ value decreases, the $V_{D C}$ has slow response and a large overshoot. As a result, the optimal initial firing angle may be determined to be between 0.1 and 0.5 in forward mode. In the case of reverse mode, the optimal initial firing angle is between 0.8 and 0.95 .

\subsection{Proposed voltage control}

In the ZCDS, DC trolley voltage is ringing or lowering because thyristor of both converters turn off to prevent short-circuit. When the voltage is less than the $V_{\min }$ or exceeds $V_{\max }$, the forward or reverse mode is started. After the mode is started, this paper proposes a control scheme for improving the response characteristics of DC trolley voltage using the optimal initial firing angle tracking algorithm.

Fig. 6 (a) shows a flow chart of the proposed control algorithm. It is the same as the conventional control algorithm until mode selection. $K_{\text {for }}$ and $K_{\text {rev }}$ are continuously adjusted to optimize the initial firing angle using the equations $K_{f o r} / K_{r e v}+=K^{*} 1000, K_{\text {for }} / K_{\text {rev }}-=$ $K^{*} 1000, K_{\text {for }} / K_{\text {rev }}+=K$, and $K_{\text {for }} / K_{\text {rev }}-=K$.

In Fig. 7, $t_{0}, t_{1}, t_{2}$, and $t_{3}$ are the starting points of the forward/reverse modes, recovery point of $V_{\max }$ or $V_{\min }$, recovery point of $V_{\text {ref }}$, and recovery point of $V_{\text {ref }}$ after overshoot, respectively. The relationships among $t_{0}-t_{3}$ and $T_{1}-T_{3}$ are shown in Table 1 . If count values of $T_{1}, T_{2}$ and $T_{3}$ are all reduced, the $V_{d c}$ response is improved. However, the priorities must be selected to improve the $V_{\mathrm{dc}}$ response because it is not possible to reduce all the count value of each interval. In the $T_{3}$ of forward/reverse mode, if the $V_{\mathrm{dc}}$ exceeds the $V_{\max }$ or is less than the $V_{\min }$, the parallel multipulse dual converter becomes unstable because it can operate reverse/forward mode without ZCDS. Therefore, $T_{3}$ was selected as the first priority. $T_{1}$ was selected as the second priority to prevent a trip to the load system. Lastly, $T_{2}$ was selected as the third priority to compensate for the fast response. Finally, the values of $T_{1 \max }, T_{2 \max }$ and $T_{3 \max }$ were selected as 30,100 and 10, respectively.

\section{Simulation Results}

Table 2 compares the actual model and scale model. The scale of the voltage and current is $1 / 20$. The scale model

Table 2. Comparison of actual model and scale model

\begin{tabular}{c|c|c}
\hline Items & Actual Model & Scale Model \\
\hline$P_{o}$ & $4 \mathrm{MW}$ & $10 \mathrm{~kW}$ \\
\hline$V_{\mathrm{ll}}^{\prime}$ & $22,900 \mathrm{~V}$ & $380 \mathrm{~V}$ \\
\hline$V_{\mathrm{ll}}$ & $1750 \mathrm{~V}$ & $87.5 \mathrm{~V}$ \\
\hline$V_{\mathrm{dc}}$ & $1600 \mathrm{~V}$ & $80 \mathrm{~V}$ \\
\hline$V_{\max } / V_{\min }$ & $1700 \mathrm{~V} / 1500 \mathrm{~V}$ & $85 \mathrm{~V} / 75 \mathrm{~V}$ \\
\hline$I_{\mathrm{dc}}$ & $2500 \mathrm{~A}$ & $125 \mathrm{~A}$ \\
\hline$I_{\max } / I_{\min }$ & $100 \mathrm{~A}$ & $5 \mathrm{~A}$ \\
\hline
\end{tabular}

can obtain the same response characteristics as the actual model. The load converter operates as a current source control to generate energy consumption and regenerative

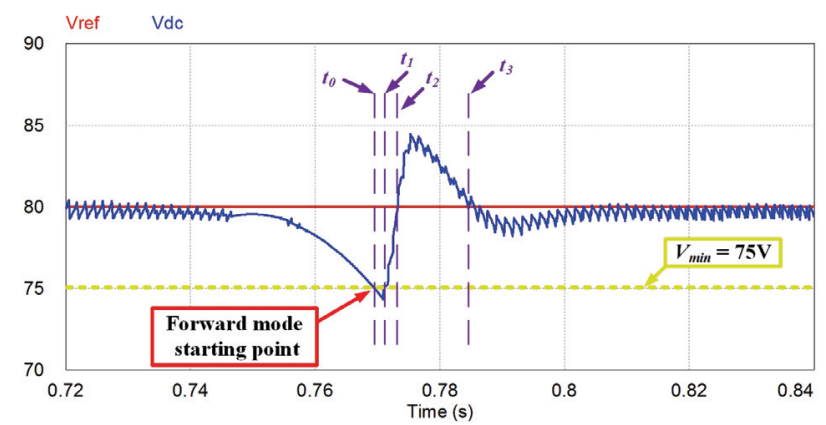

(a)

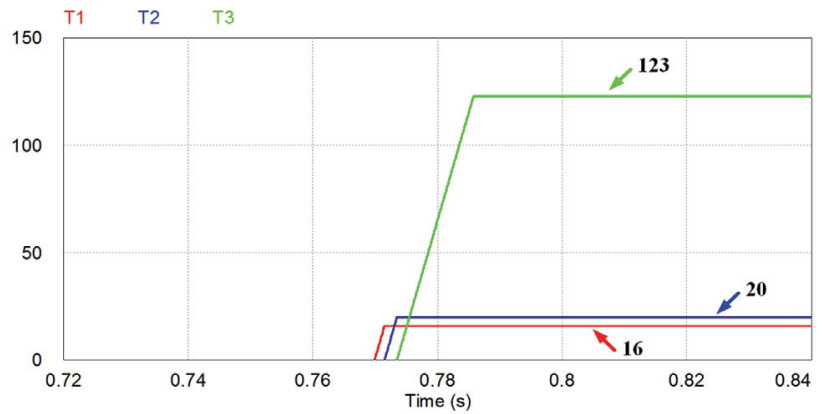

(b)

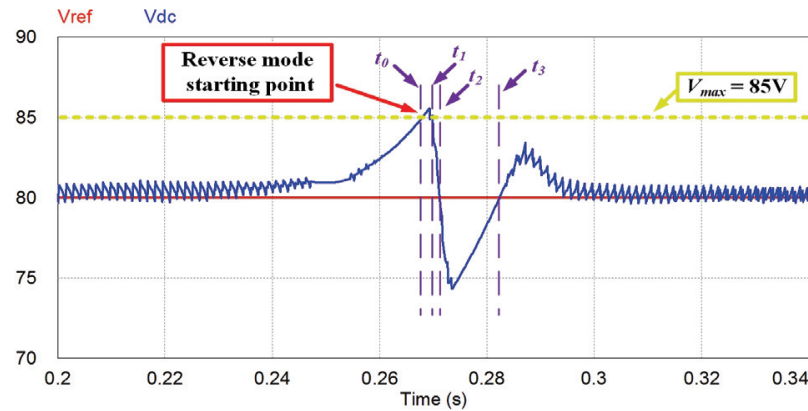

(c)

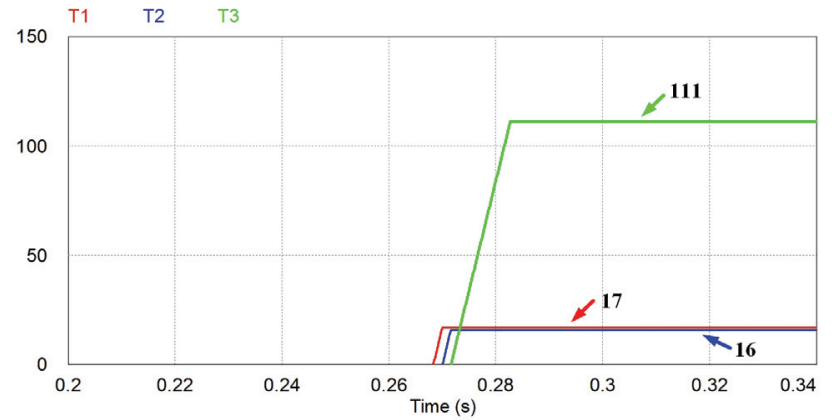

(d)

Fig. 7. Point selection and count values according to response characteristics of DC trolley voltage in forward/reverse mode: (a) $V_{d c}$ and starting points of $t_{0}-t_{3}$ (Forward mode, $P I_{\text {out }}=0.5$ p.u.) (b) Count values of $T_{1}, T_{2}, T_{3}$ (Forward mode, $P I_{\text {out }}=0.5$ p.u.) (c) $V_{d c}$ and starting points of $t_{0}-t_{3}$ (Reverse mode, $P I_{\text {out }}=0.8$ p.u.) (d) Count values of $T_{1}, T_{2}, T_{3}$ (Reverse mode, $P I_{\text {out }}=0.8$ p.u.) 
energy. The reference current is a triangular-wave current source. The frequency of the reference current is $1 \mathrm{~Hz}$. The peak-to-peak current amplitude is $250 \mathrm{~A}$.

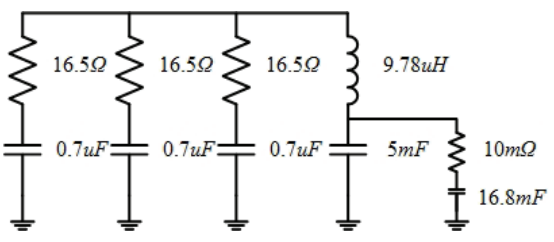

(a)

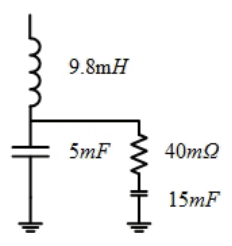

(b)
Fig. 8. Equivalent circuits of differential DC filters: (a) Filter 1 (b) Filter 2

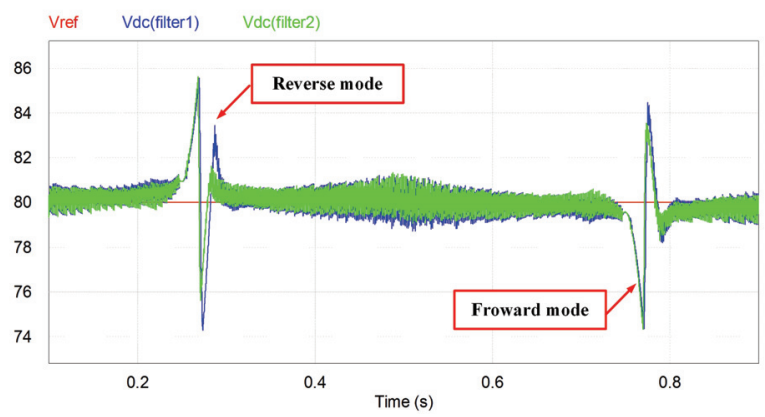

Fig. 9. Response characteristics of DC trolley voltage for filters 1 and 2 (Forward mode: $P I_{\text {out }}=0.5$ p.u., reverse mode: $P I_{\text {out }}=0.8$ p.u.)

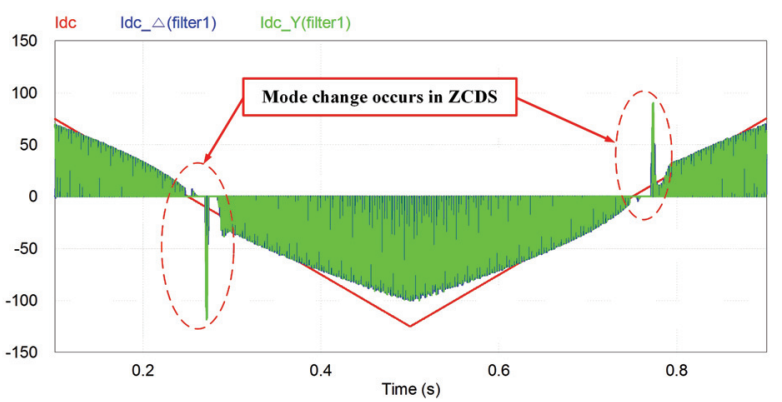

(a)

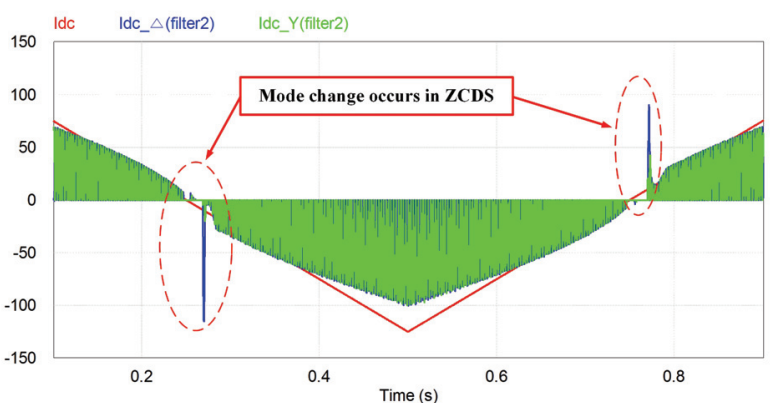

(b)

Fig. 10. Response characteristics of $\boldsymbol{I}_{\boldsymbol{d} \boldsymbol{c}_{-} \boldsymbol{\Delta}}$ and $\boldsymbol{I}_{\boldsymbol{d} \boldsymbol{c}_{-} \boldsymbol{Y}}$ using conventional control for filters 1 and 2 . (Forward mode: $P I_{\text {out }}=0.5$ p.u., reverse mode: $P I_{\text {out }}=0.8$ p.u.) (a) Filter 1 (b) Filter 2

\subsection{Comparison of characteristics for different filters}

To verify the performance of the proposed algorithm, two types of DC filter are designed assuming differences in the line impedances such as the traction transformers, $\mathrm{AC}$ filter, DC filter, and trolley line impedance. The equivalent circuit and parameters of the DC filters are shown Fig. 8.

Fig. 9 shows the response characteristics of the DC trolley voltage for filters 1 and 2. Both filters are applied at the same constant $P I_{\text {out }}$ values and PI gain values: forward mode $\left(P I_{\text {out }}=0.5\right.$ p.u. $)$ and reverse mode $\left(P I_{\text {out }}=0.8\right.$ p.u. $)$. The PI gain values were chosen as $k_{\mathrm{p}}=2.0, k_{\mathrm{i}}=0.023$, and $k_{\mathrm{c}}=0.75$; In forward mode, filter 1 has a larger overshoot than filter 2. In reverse mode, filter 1 has a larger overshoot and slow response than filter 2 .

Fig. 10 and Fig. 11 show response characteristics of $\mathbf{I}_{\boldsymbol{d c} \_\boldsymbol{\Delta}}$ and $\mathbf{I}_{d c_{\boldsymbol{Y}} \boldsymbol{Y}}$, and count values of $T_{1}, T_{2}$, and $T 3$ for filters 1 and 2. Due to the count values of $T_{3}$ are large both filters 1 and 2, mode change occurs in ZCDS, and then $\mathbf{I}_{\boldsymbol{d c} \boldsymbol{\Delta}}$ and $\mathbf{I}_{\boldsymbol{d} c_{-} \boldsymbol{Y}}$ occur large overshoot. In addition, it was confirmed that the optimal initial firing angle is different depending on the line impedance of each converter because of the difference of count values for the filters 1 and 2 , as shown Fig. 11. Therefore, the different optimal initial firing angles must be applied to each converter.

\subsection{Proposed control algorithm for filters 1 and 2}

The simulation is based on a 32-bit fixed-point digital

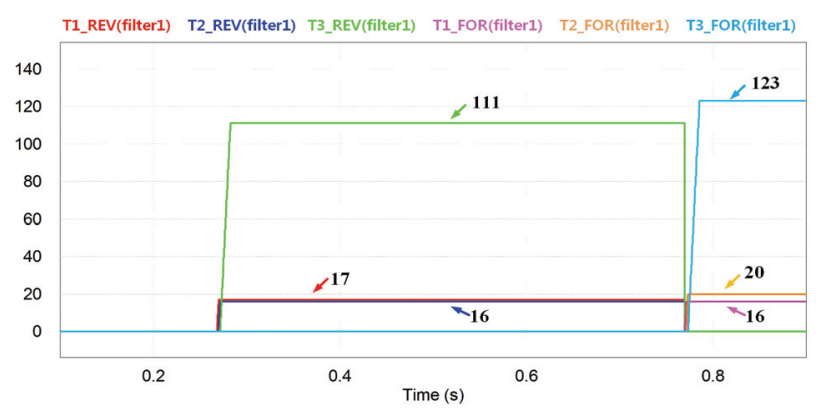

(a)

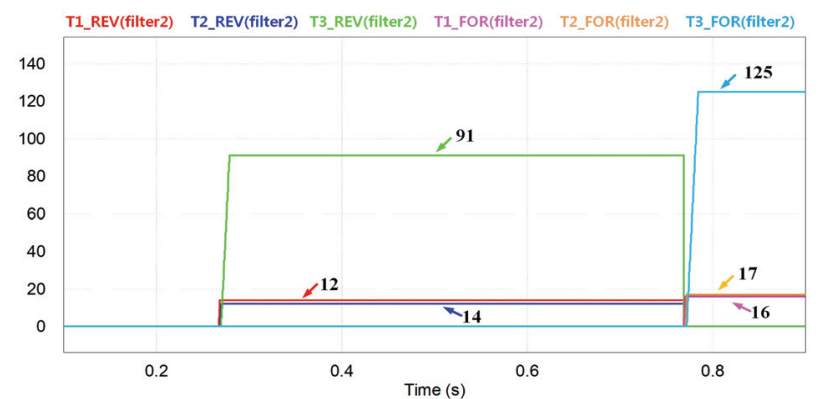

(b)

Fig. 11. Count values of $T_{1}, T_{2}, T_{3}$ using conventional control for filters 1 and 2 (Forward mode: $P I_{\text {out }}=$ 0.5 p.u., reverse mode: $P I_{\text {out }}=0.8$ p.u.): (a) Filter 1 (b) Filter 2 
signal processing (TMS 320F28335). The sampling frequency for measuring $V_{\mathrm{dc}}$ and $I_{\mathrm{dc}}$ is $10 \mathrm{kHz}$. The PI control frequency is $10 \mathrm{kHz}$. The resolution of the PI controller is based on IQ15. Therefore, the minimum value of $K$ can be expressed as

$$
K=\frac{p \cdot u}{Q 15}=\frac{1}{2^{15}}=0.00003051757813
$$

The minimum firing angle for the proposed control algorithm is obtained as

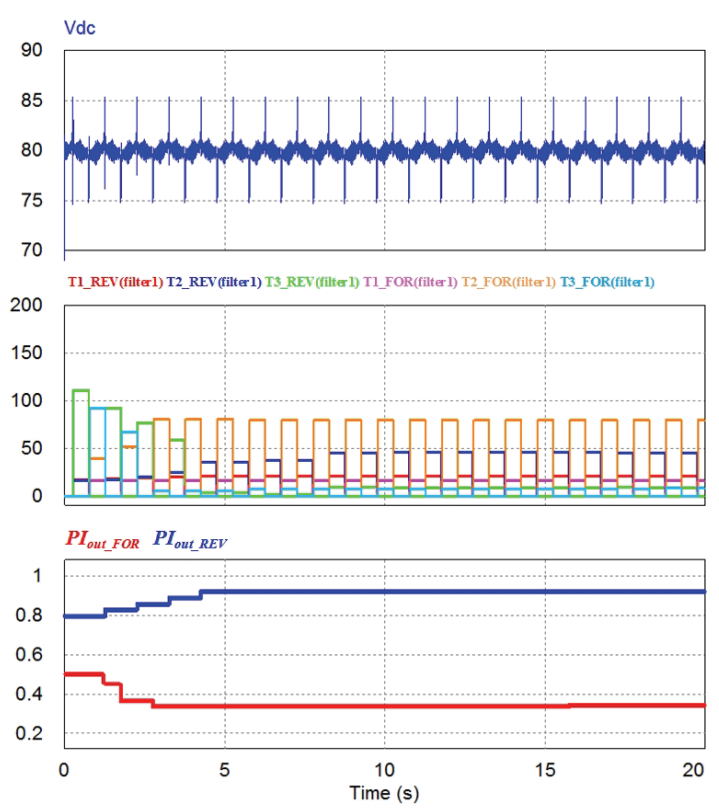

(a)

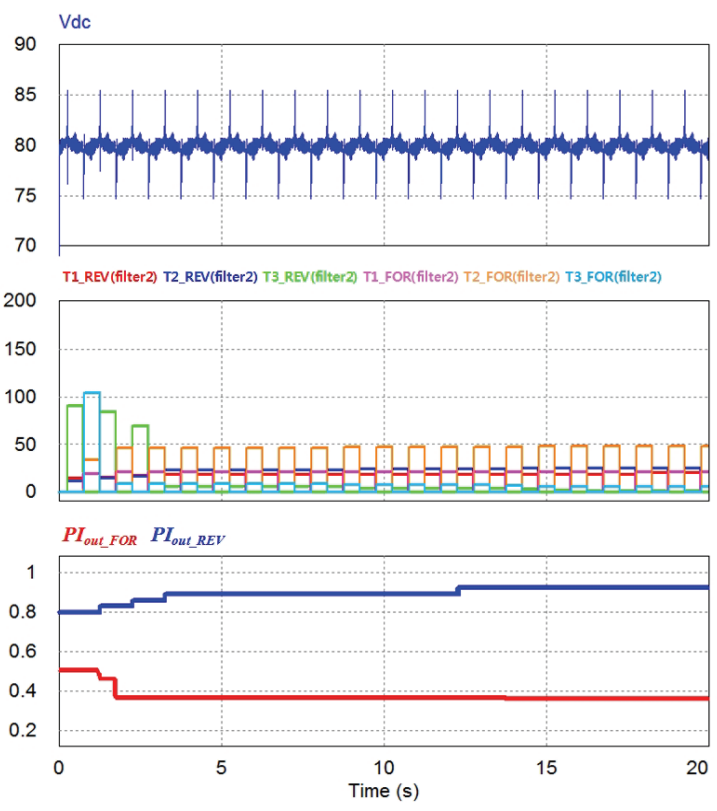

(b)

Fig. 12. Response characteristics comparison using proposed control for filters 1 and 2: (a) Filter 1 (b) Filter 2

$$
\alpha=\cos ^{-1}(K)=0.001748528428^{\circ}
$$

Fig. 12 shows the response characteristics comparison for filters 1 and 2 using the proposed control. When the proposed algorithm is started, it will tracking the optimal initial firing angle. Consequently, the count values of $T_{1}, T_{2}$ and $T_{3}$ were all reduced.

Table 3 shows the initial firing angles selected using the proposed control algorithm. When the optimal firing angles has been tracking, Table 4 shows the count values of $T_{1}, T_{2}$ and $T_{3}$ using the proposed control for filters 1 and 2 . Compared with the count values of Fig. 11, each count value satisfy within the $T_{1 \max }, T_{2 \max }$ and $T_{3 \max }$.

Fig. 13 shows the DC trolley voltage response comparison of two converters using the proposed control with different filters. Except for the difference in the amplitude of the DC trolley voltage caused by the frequency response of each filter, each converter has substantially the same response.

Fig. 14 shows the response characteristics of $\mathbf{I}_{\boldsymbol{d c} \_\boldsymbol{\Delta}}$ and $\mathbf{I}_{\boldsymbol{d c} \boldsymbol{Y} \boldsymbol{Y}}$ using proposed control for filters 1 and 2. Compared with Fig. 10, the mode change does not occur in ZCDS and the large overshoot of the current does not appear.

Table 3. Simulation results of optimal initial firing angles selected using the proposed control algorithm for filters 1 and 2

\begin{tabular}{c|c|c|c|c}
\hline \multirow{2}{*}{ Type } & \multicolumn{2}{|c|}{ Forward mode } & \multicolumn{2}{c}{ Reverse mode } \\
\cline { 2 - 5 } & $P I_{\text {out }}$ & $\alpha$ & $P I_{\text {out }}$ & $\alpha$ \\
\hline Filter 1 & 0.3267 & $70.93^{\circ}$ & 0.9257 & $22.22^{\circ}$ \\
\hline Filter 2 & 0.3624 & $68.75^{\circ}$ & 0.9032 & $25.42^{\circ}$ \\
\hline
\end{tabular}

Table 4. Simulation results of count values of $T_{1}, T_{2}$ and $T_{3}$ using the proposed control algorithm for filters 1 and 2

\begin{tabular}{c|c|c}
\hline Items & Filter 1 & Filter 2 \\
\hline$T_{1 \_R E V}$ & 16 & 18 \\
\hline$T_{2 \_R E V}$ & 80 & 26 \\
\hline$T_{3 \_R E V}$ & 9 & 3 \\
\hline$T_{1 \_F O R}$ & 21 & 21 \\
\hline$T_{2 \_F O R}$ & 45 & 48 \\
\hline$T_{3 \_F O R}$ & 9 & 6 \\
\hline
\end{tabular}

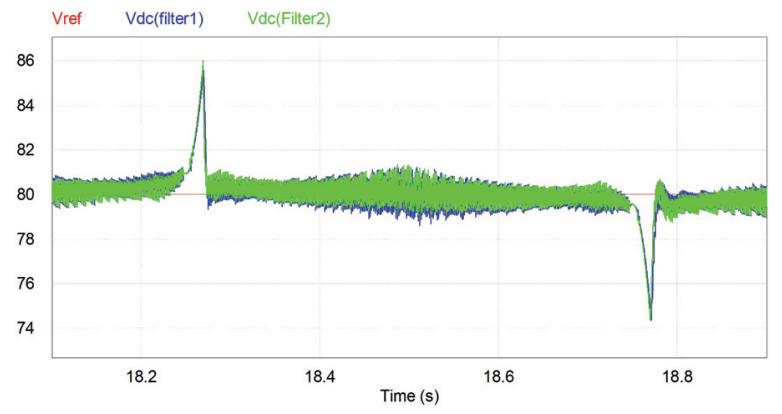

Fig. 13. Voltage response comparison of two converters using the proposed control with different filters 


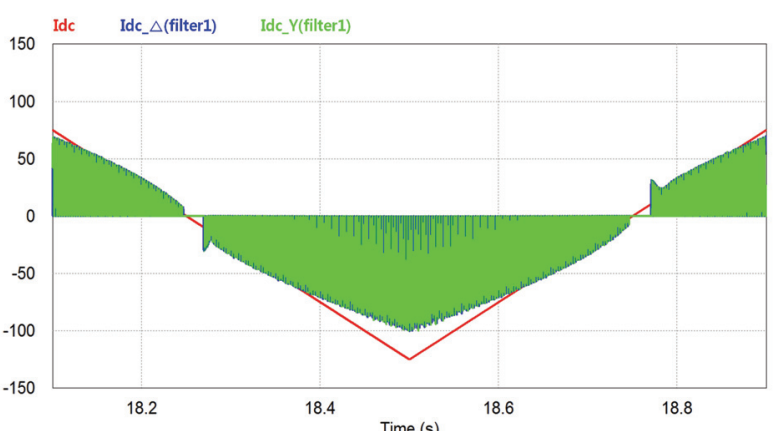

(a)

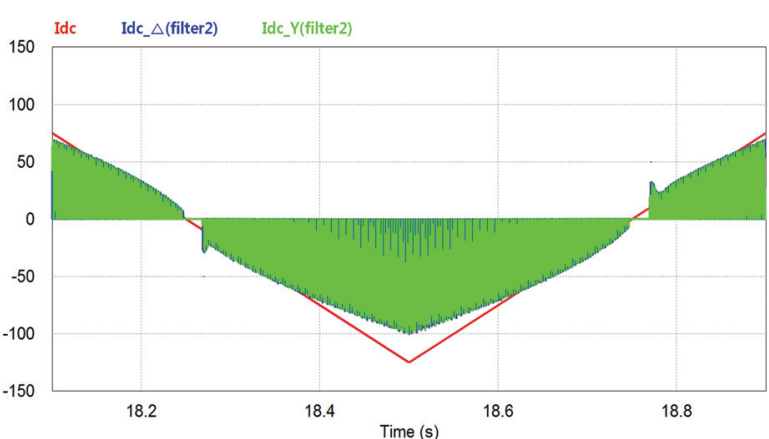

(b)

Fig. 14. Response characteristics of $I_{d c} \Delta$ and $I_{d c} Y$ for filters 1 and 2 using proposed control. (a) Filter 1 (b) Filter 2

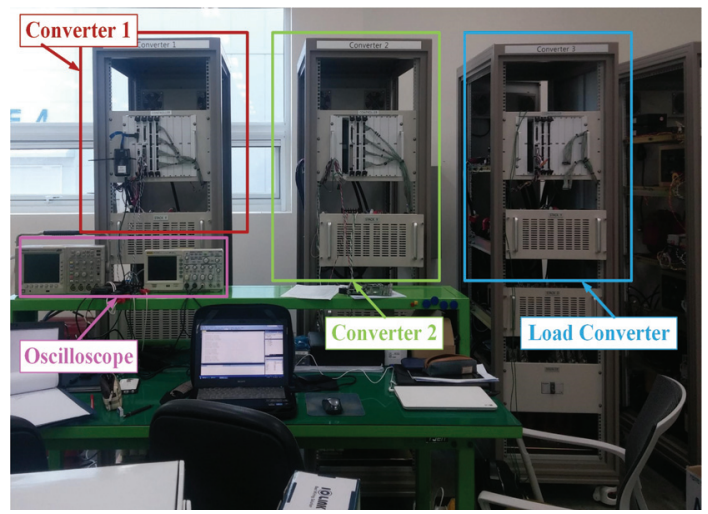

Fig. 15. Experimental setup

\section{Experimental Results}

The experimental setup is shown in Fig. 15. To verify the performance of the proposed algorithm, the converters 1 and 2 are connected filters 1 and 2 in parallel, respectively. To consider the operating conditions of trains, the load converter was used as the current source in the simulation, as shown Fig. 16 and Fig. 17.

Fig. 16 (a) and (b) show the conventional control response with filters 1 and 2 . The conventional control was applied to the constant $P I_{\text {out }}$ values in the simulation: forward mode $\left(P I_{\text {out }}=0.8\right.$ p.u. $)$ and reverse mode $\left(P I_{\text {out }}=\right.$
Table 5. Experimental results of optimal initial firing angles selected using the proposed control algorithm for filters 1 and 2

\begin{tabular}{c|c|c|c|c}
\hline \multirow{2}{*}{ Type } & \multicolumn{2}{|c|}{ Forward mode } & \multicolumn{2}{c}{ Reverse mode } \\
\cline { 2 - 5 } & $P I_{\text {out }}$ & $\alpha$ & $P I_{\text {out }}$ & $\alpha$ \\
\hline Filter 1 & 0.3288 & $70.80^{\circ}$ & 0.9312 & $21.38^{\circ}$ \\
\hline Filter 2 & 0.3712 & 68.21 & 0.9131 & $24.06^{\circ}$ \\
\hline
\end{tabular}

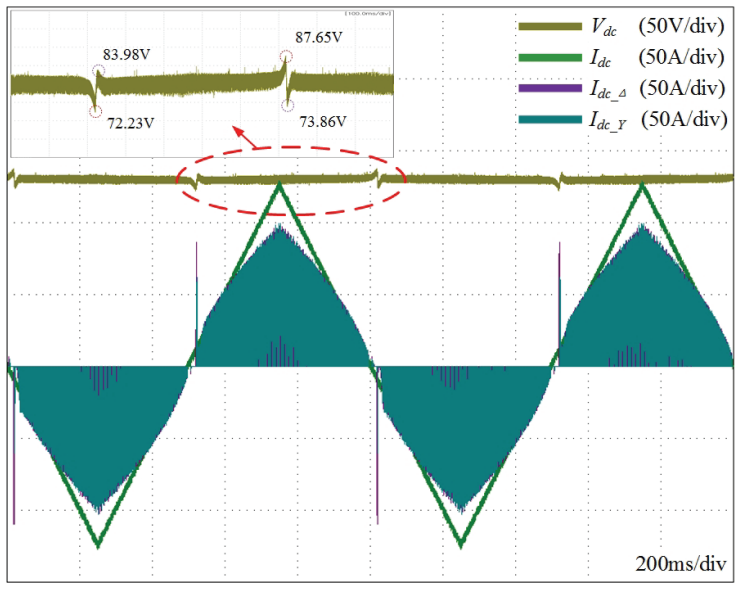

(a)

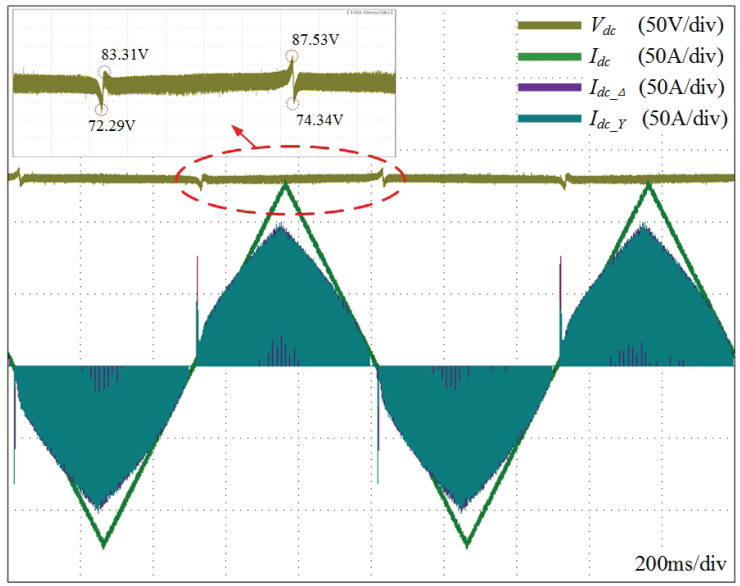

(b)

Fig. 16. Experimental waveforms under conventional control: forward mode $\left(P I_{\text {out }}=0.5\right.$ p.u. $)$ and reverse mode $\left(P I_{\text {out }}=0.8\right.$ p.u. $)$ : (a) Conventional control with filter 1 (b) Conventional control with filter 2

0.5 p.u.). Both filter 1 and filter 2 exhibit the slow response and overshoots. In the case of the current, the mode change occurs in ZCDS, and then $I_{d c_{-} \Delta}$ and $I_{d c_{-} Y}$ occur large overshoot.

Table 5 shows the initial firing angles selected using the proposed control algorithm. When the optimal firing angles has been tracking, Table 6 shows the count values of $T_{1}, T_{2}$ and $T_{3}$ using the proposed control for filters 1 and 2 .

After the proposed control is applied, the voltage response is faster than that of the conventional control and 
Table 6. Experimental results of count values of $T_{1}, T_{2}$ and $T_{3}$ using the proposed control algorithm for filters 1 and 2

\begin{tabular}{c|c|c}
\hline Items & Filter 1 & Filter 2 \\
\hline$T_{1 \_R E V}$ & 19 & 21 \\
\hline$T_{2}$ REV & 95 & 28 \\
\hline$T_{3, R E V}$ & 7 & 5 \\
\hline$T_{1 \_F O R}$ & 25 & 23 \\
\hline$T_{2}$ FOR & 48 & 55 \\
\hline$T_{3 \_F O R}$ & 10 & 7 \\
\hline
\end{tabular}

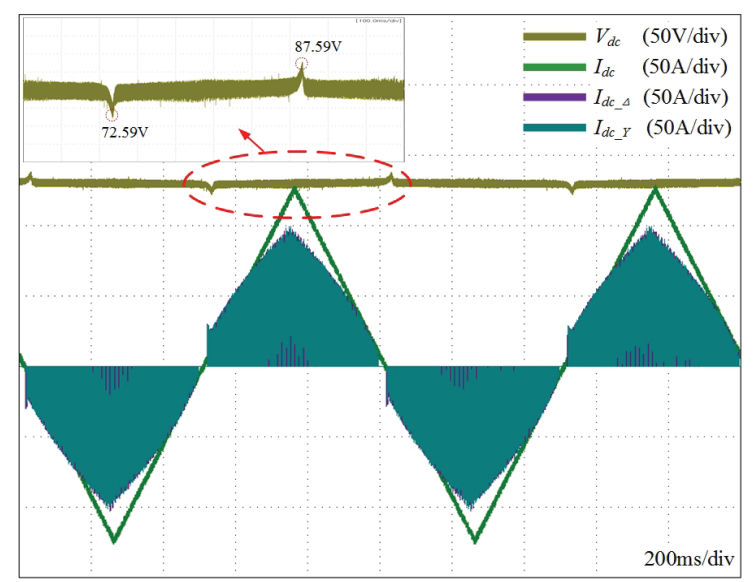

(a)

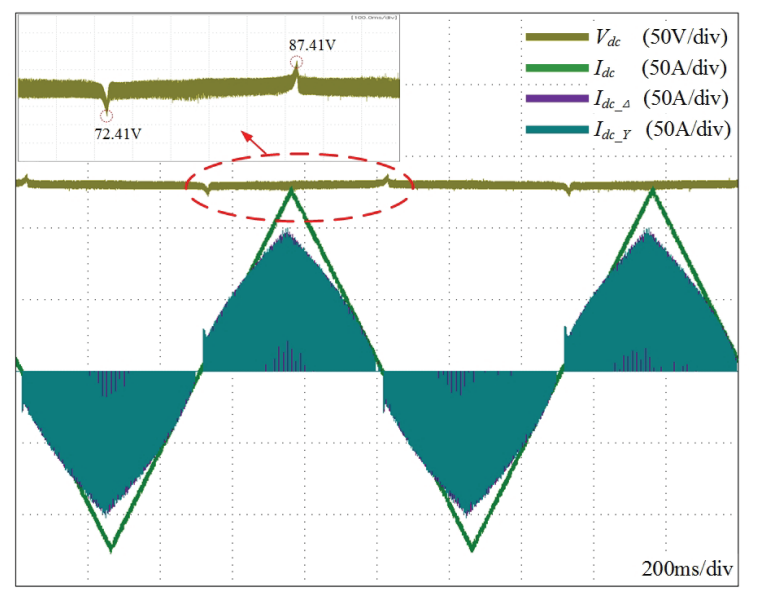

(b)

Fig. 17. Experimental waveforms under conventional control and proposed control (a) Conventional control with filter 1: forward mode $\left(P I_{\text {out }}=0.3288\right.$ p.u.) and reverse mode $\left(P I_{\text {out }}=0.9312\right.$ p. u. $)(b)$ Conventional control with filter 2: forward mode $\left(P I_{\text {out }}=0.3712\right.$ p.u. $)$ and reverse mode $\left(P I_{\text {out }}=\right.$ 0.9131 p.u.)

there are no indications of the large overshoot and slow response, as shown in Fig. 17. In addition, the mode change does not occur in ZCDS and the large overshoot of the current does not appear. The values are a little lager than that of the simulation one. However, these results are acceptable.

\section{Conclusion}

In a parallel multi-pulse thyristor dual converter for urban railway power substations, the stability of the DC trolley voltage varies according to the initial firing angle. In the conventional control algorithm, the initial firing angles are experimentally selected as the constant values. However, the optimal firing angle varies with various impedances. In this paper, optimal initial firing angle control was proposed for maintaining a stable DC trolley voltage. The slow response and overshoot of the DC trolley voltage are eliminated by optimal initial firing angle control in the parallel multi-pulse thyristor dual converter. The designed control algorithm was verified through simulations and experiments.

\section{Acknowledgements}

This research was supported by railway technical research program through the Korean Agency for infrastructure Technology Advancement(15RTRP-B091404-02) and by Basic Science Research Program through the National Research Foundation of Korea Grant Funded by the Korea Government No: NRF-2014R1A2A2A01003368.

\section{References}

[1] Y. Jiang, J. Liu, W. Liu, W. Tian, M. Shahidehpour, and M. Krishnamurthy, "Energy harvesting for the electrification of railway stations: Getting a charge from the regenerative braking of trains. A," IEEE Electrification Mag., vol. 2, pp. 39-48, 2014.

[2] T. Ratniyomchai, S. Hillmansen, and P. Tricoli, "Recent developments and applications of energy storage devices in electrified railways," IET Electr. Syst. Transp., vol. 4, pp. 9-20, 2014.

[3] M. Hasan Ali, B. Wu, and R. A. Dougal, "An overview of SMES applications in power and energy systems," IEEE Trans. Sustain. Energy, vol. 1, pp. 38-47, Apr. 2010.

[4] T. A. Aanstoos, J. P. Kajs, W. G. Brinkman, H. P. Liu, A. Ouroua, R. J. Hayes, C. Hearn, J. Sarjeant, and H. Gill, "High voltage stator for a flywheel energy storage system," IEEE Trans. Magn., vol. 37, pp. 242-247, 2001.

[5] S. R. Gurumurthy, V. Agarwal, and A. Sharma, "Optimal energy harvesting from a high-speed brushless DC generator-based flywheel energy storage system," IET Electr. Syst. Transp., vol. 7, pp. 693-700, 2013.

[6] David J. Perreaul, John G. Kassakian. "Effects of firing angle imbalance on 12-pulse," IEEE Trans. Power Electron., vol. 10, no. 3, May. 1995.

[7] S. W. Han, S. K. Kim, S. H. Park, C. H. Lee, and H. Y. 
Yoo. "Development of Double Converter Substation with Control Algorithm and Parallel Operation Method for Electric Railway Power System," Conf. International Journal of Railway, pp. 223-228, 2015.

[8] S. W. Han, C. H. Lee, Y. W. Kim and D. O. Moon, "Control algorithm of thyristor dual converter power system for railway power substations," Transactions of the Korean Institute of Power Electronics, vol. 20, no.6, pp. 573-579. Dec. 2015.

[9] S. A. Kim, G. J. Han, S. W. Han and Y. H. Cho, "Study on Parallel Operation Control of Dual Converter for Urban Railway DC Power Substations," Conf. KIEE, pp. 999-1000, July 2016.

[10] C. S. Jang, S. A. Kim, S. W. Han and Y. H. Cho, “A study on output characteristics according to initial firing angle of double converter," Conf. KIEE, pp. 978-979, July 2015.

[11] S. J. Jeong and S. H. Song, "Improvement of predictive current control performance using online parameter estimation in phase controlled rectifier," IEEE Trans. Power Electron., vol. 22, pp. 1820-1825, 2007.

[12] C. Lee, H. Liu, K. Hwang, S. Lee, H. Park, C. Kim, J. S. Oh, J. H. Suh, J. Choi, S. J. Jeong, and, S. H. Song, "A novel control for four-quadrant operation of ITER VS converter," in 2013 Int. Conf. Electrical Machines and Systems (ICEMS), pp. 1657-1661, 2013.

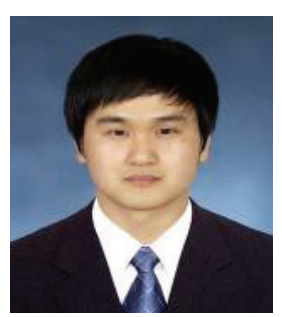

Sung-An Kim He received B.S and M.S degree in electrical engineering from Dong-A University in 2011 and 2013 respectively. In 2015, he joined Dong-A University, Power Electronics Applications Laboratory (PEAL), as Senior Researcher. $\mathrm{He}$ is currently working toward the Ph.D. degree in electrical engineering with Dong-A university. His research interests are electrical machine and power electronics.

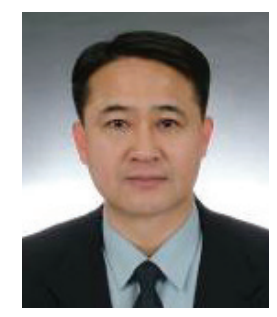

Sung-Wo Han He received B.S and M.S degrees in electrical engineering from Dong-A university in 1985 and 2015. In 1990, he joined Busan Transportation Corporation, R\&D center, as Researcher. He is currently working toward the Ph.D. degree in electrical engineering with Pukyong National University. His research interests are urban railway power substations and power electronics.

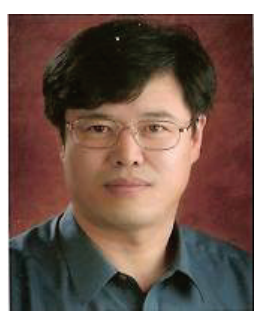

Yun-Hyun Cho He received B.S and M.S degree in electrical engineering from Han-Yang University in 1986 and 1991 respectively. From 1990 to 1995, he was a senior researcher at Korea Electro-technology Research Institute (KERI). In 1995, he joined Dong-A University, Department of Electrical Engineering, as Professor. His research interests are electrical machine and power electronics. 